3 Brannan JD, Anderson SD, Perry CP, et al. The safety and efficacy of inhaled dry powder mannitol as a bronchial provocation test for airway hyperresponsiveness: a phase 3 comparison study with hypertonic (4.5\%) saline. Respir Res 2005; 6: 144

4 Beydon N, Davis SD, Lombardi E, et al. An official American Thoracic Society/European Respiratory Society statement: pulmonary function testing in preschool children. Am J Respir Crit Care Med 2007; 175: $1304-1345$.

5 Hall GL, Gangell C, Fukushima T, et al. Application of a shortened inhaled adenosine-5'-monophosphate challenge in young children using the forced oscillation technique. Chest 2009; 136: 184-189.

6 Horsman TA, Duke RK, Davenport PW. Airway response to mannitol challenge in asthmatic children using impulse oscillometry. J Asthma 2009; 46: 600-603.

7 Malmberg LP, Mäkelä MJ, Mattila PS, et al. Exercise-induced changes in respiratory impedance in young wheezy children and nonatopic controls. Pediatr Pulmonol 2008; 43: 538-544.

\title{
Heart failure impairs cerebral oxygenation during exercise in patients with COPD
}

\author{
To the Editor:
}

Impaired systemic oxygen delivery, particularly during exertion, is the key pathophysiological feature shared by chronic obstructive pulmonary disease (COPD) and heart failure with reduced left ventricular ejection fraction (HFrEF). Unfortunately, COPD and HFrEF frequently coexist not only because of their high individual prevalence but also due to common risk factors, including cigarette smoking, advanced age, oxidative stress and systemic inflammation [1].

It is expected that any reduction in the rate of oxygen transfer due to COPD and/or HFrEF would be particularly deleterious to tissues heavily dependent upon constant oxygen flow, such as the central nervous system (as reviewed in [2]). Exercise cerebral oxygenation (Cox) (as noninvasively determined by nearinfrared spectroscopy) depends upon the dynamic balance between the instantaneous rate of oxygen delivery and oxygen utilisation [3]. KoIKe et al. [4], for instance, reported that congestive heart failure (CHF) HFrEF was associated with appreciable decreases in COx during exertion. Our laboratory found that exercise COx might be impaired in some patients with more advanced COPD, even if not overtly hypoxaemic [5]. Moreover, improvement in cardiac output with noninvasive ventilation (under the same arterial oxygen content) had positive effects on COx in COPD [6]. These data suggest that reduced cerebral blood flow might be mechanistically linked to impaired exercise COx in some patients with moderate-tosevere COPD. It is conceivable that the presence of HFrEF would further deteriorate this scenario by adding components of dysfunctional cerebral autoregulation, lower cardiac output and hypocapnia-induced vasoconstriction [4]. The compound effects of HFrEF plus COPD on COx and its relationship with exercise tolerance, however, remain unknown. In order to address these issues, we simultaneously assessed COx, systemic haemodynamics and gas exchange during progressive exercise in COPD patients presenting or not with HFrEF as a comorbidity.

33 males with stable, nonhypercapnic (arterial carbon dioxide tension $<45 \mathrm{mmHg}$ at rest) COPD with a long history of smoking ( $>20$ pack-years), breathlessness in daily life (modified Medical Research Council $(\mathrm{MRC})$ scale scores $>2$ ) and moderate-to-severe airflow obstruction comprised the study group. Patients from the COPD+HFrEF group $(n=18)$ presented with left ventricular ejection fraction by Doppler echocardiography $<40 \%$ and well-established diagnosis of CHF (dyspnoea on exertion, elevated jugular venous pressure, cardiomegaly, peripheral oedema and pulmonary crepitations) due to underlying ischaemic heart disease. All patients were under standard contemporary therapy for HFrEF. 15 patients from the COPD clinic without clinical, echocardiographic and laboratorial evidence of CHF $(n=15)$ were matched by age and MRC grade (table 1). The main exclusion criteria included long-term ambulatory oxygen therapy, severe pulmonary hypertension (mean pulmonary artery pressure $\geqslant 40 \mathrm{~mm} \mathrm{Hg}$ ), anaemia (haemoglobin concentration $<13 \mathrm{~g} \%$ ), and recent exacerbation (within 1 month). After providing informed consent (as approved by the local medical ethics committee), patients underwent a rampincremental cardiopulmonary exercise test with assessment of arterialised carbon dioxide tension $\left(\mathrm{PCO}_{2}\right)$. Changes from rest $(\Delta)$ in pre-frontal COx (oxyhaemoglobin concentration $\left(\left[\mathrm{HbO}_{2}\right]\right)$ ) were measured by near infrared spectroscopy (NIRO 200 ${ }^{\mathrm{TM}}$; Hamamatsu Photonics KK, Hamamatsu, Japan) and cardiac output by transthoracic cardioimpedance (PhysioFlow PF-5 ${ }^{\mathrm{TM}}$; Manatec Biomedical, Paris, France) [7]. Based on a pooled analysis of our previous data in normal older subjects and patients with COPD $[5,6]$, 
TABLE 1 Resting and exercise characteristics in chronic obstructive pulmonary disease (COPD) patients with or without heart failure with reduced ejection fraction (HFrEF) as a comorbidity

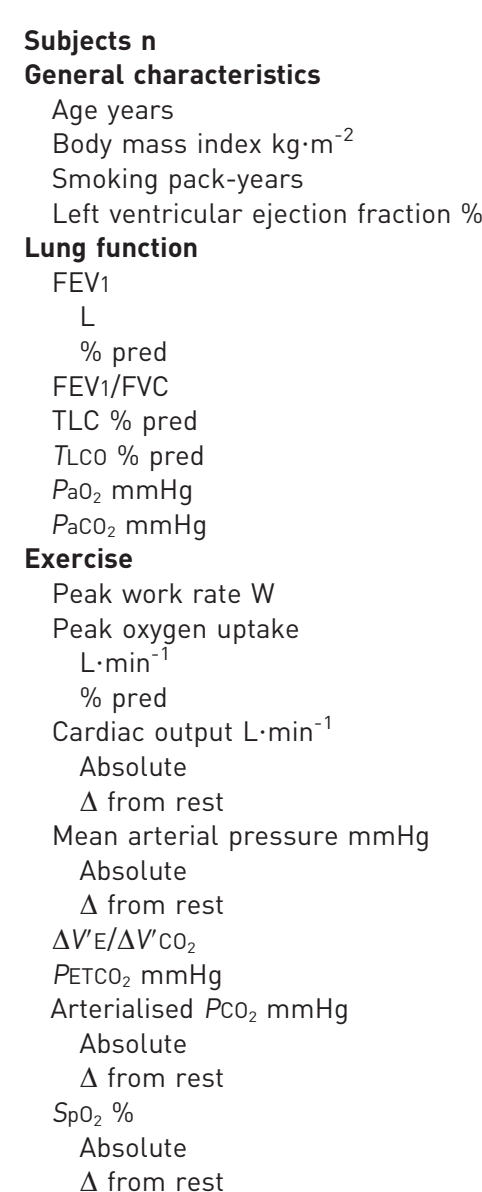

COPD+HFrEF

COPD

\begin{tabular}{|c|c|}
\hline 18 & 15 \\
\hline $\begin{array}{c}67 \pm 7 \\
25.0 \pm 4.1 \\
51.3 \pm 30.1 \\
35.3 \pm 7.6^{*}\end{array}$ & $\begin{array}{c}65 \pm 8 \\
24.2 \pm 3.9 \\
45.5 \pm 26.5 \\
64.9 \pm 3.8\end{array}$ \\
\hline $\begin{array}{c}1.70 \pm 0.52 \\
64.1 \pm 18.3^{*} \\
63.1 \pm 9.3^{*} \\
83.5 \pm 22.5^{*} \\
51.4 \pm 14.2 \\
65.3 \pm 7.0 \\
34.1 \pm 3.3\end{array}$ & $\begin{array}{c}1.31 \pm 0.64 \\
46.3 \pm 15.6 \\
41.7 \pm 9.4 \\
109.3 \pm 12.6 \\
56.9 \pm 16.1 \\
61.9 \pm 9.2 \\
37.6 \pm 6.6\end{array}$ \\
\hline $53 \pm 24$ & $65 \pm 24$ \\
\hline $\begin{array}{c}1.03 \pm 0.32^{*} \\
52 \pm 12^{*}\end{array}$ & $\begin{array}{c}1.21 \pm 0.30 \\
64 \pm 14\end{array}$ \\
\hline $\begin{array}{l}8.9 \pm 2.6^{*} \\
3.1 \pm 1.8^{*}\end{array}$ & $\begin{array}{c}10.9 \pm 3.0 \\
4.3 \pm 1.5\end{array}$ \\
\hline $\begin{array}{c}99 \pm 20^{*} \\
8 \pm 5^{*} \\
38.7 \pm 9.3^{*} \\
31.8 \pm 5.8^{*}\end{array}$ & $\begin{array}{c}120 \pm 14 \\
22 \pm 7 \\
28.8 \pm 7.2 \\
37.6 \pm 6.1\end{array}$ \\
\hline $\begin{array}{c}32.4 \pm 5.2^{*} \\
0.6 \pm 2.3^{*}\end{array}$ & $\begin{array}{c}38.1 \pm 6.7 \\
4.7 \pm 2.1\end{array}$ \\
\hline $\begin{array}{c}93 \pm 3^{*} \\
0 \pm 3^{*}\end{array}$ & $\begin{array}{l}90 \pm 6 \\
-4 \pm 3\end{array}$ \\
\hline
\end{tabular}

Data are presented as mean \pm SD, unless otherwise stated. FEV1: forced expiratory volume in $1 \mathrm{~s} ; \%$ pred: $\%$ predicted; FVC: forced vital capacity; TLC: total lung capacity; TLCO: transfer factor of the lung for carbon monoxide; $\mathrm{PaO}_{2}$ : arterial oxygen tension; $\mathrm{PaCO}_{2}$ : arterial carbon dioxide tension; $\Delta$ : change; $V^{\prime} \mathrm{E}$ : minute ventilation; $V^{\prime} \mathrm{CO}_{2}$ : carbon dioxide output; $P$ ETCO${ }_{2}$ : end-tidal carbon dioxide tension; $\mathrm{PCO}_{2}$ : carbon dioxide tension; $\mathrm{SpO}_{2}$ : arterial oxygen saturation measured by pulse oximetry. ${ }^{*}: \mathrm{p}<0.05$.

$\Delta \mathrm{COx}$ increases $<1.10$ fold and/or any reduction were assumed to indicate a physiologically inadequate response. One-way ANOVA with repeated measures was used to identify statistically significant betweengroup differences across different time-points. Pearson's correlation analysis was used to assess association between variables. For all tests, a statistical significance of 0.05 was used.

We found that COPD+HFrEF patients had lower maximal exercise capacity than their counterparts with COPD. In addition, the former group showed increased ventilatory response to metabolic demand, which was associated with greater oxygen saturation (fig. 1b) but lower arterialised and end-tidal $P_{\mathrm{CO}_{2}}$ than their counterparts with COPD (table 1). COPD+HFrEF patients showed blunted haemodynamic responses (cardiac output and mean arterial pressure) during submaximal (fig. 1c and d) and maximal exercise (table 1). Changes in $\triangle \mathrm{COx}$ with exercise progression were also reduced in the COPD+HFrEF group (fig. 1a). In fact, whereas $\Delta \mathrm{COx}$ increased in 11 (73.3\%) out of 15 patients with COPD it remained stable or even decreased in $14(77.7 \%)$ out of 18 patients with COPD+HFrEF. $\Delta$ COx was particularly impaired in patients in whom mean systemic arterial pressure remained stable or decreased $(p<0.05)$. Interestingly, 

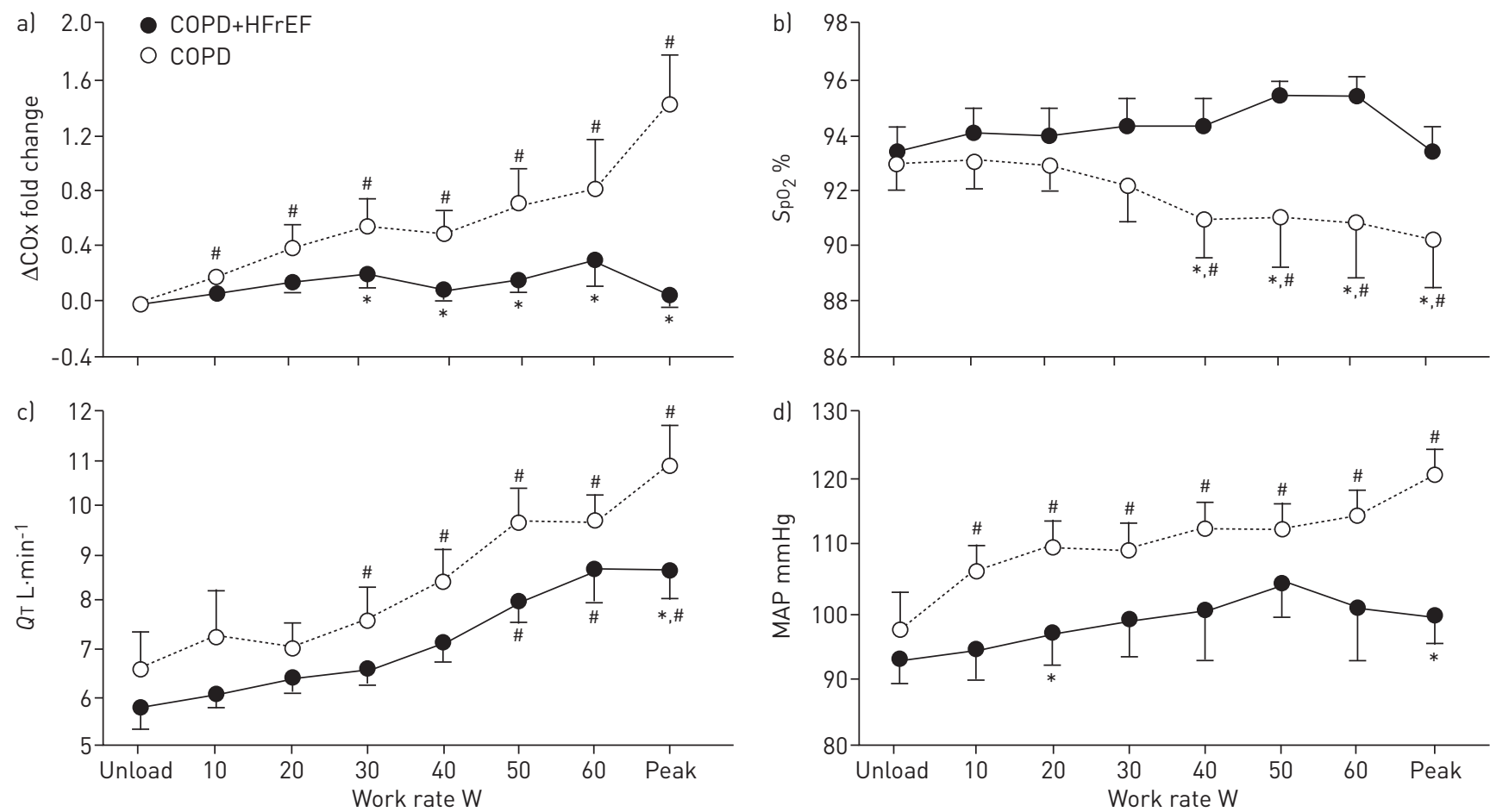

FIGURE 1 Changes in a) pre-frontal cerebral oxygenation $(\triangle \mathrm{COx}), \mathrm{b})$ arterial oxygen saturation measured by pulse oximetry $\left(\mathrm{SpO}_{2}\right)$, c) cardiac output $(Q \mathrm{Q})$ and d) mean arterial pressure (MAP) as a function of exercise intensity in chronic obstructive pulmonary disease (COPD) patients with or without heart failure with reduced ejection fraction (HFrEF) as comorbidity. Data are presented as mean \pm SE. ${ }^{*}: \mathrm{p}<0.05$ for between-group comparisons; ${ }^{\#}: \mathrm{p}<0.05$ for intragroup comparisons against unloaded cycling.

peak work rate was related to submaximal $\triangle \mathrm{COx}$ (area under the curve to an iso-work rate of $40 \mathrm{~W}$ ) only in the COPD+HFrEF group $(\mathrm{r}=0.67, \mathrm{p}<0.01)$.

Lower arterial oxygen content could be a potential explanation for reduced COx in COPD+ HFrEF, as CHF per se can reduce lung diffusing capacity, worsen ventilation/perfusion mismatch and decrease mixed oxygen venous pressure. However, we found the opposite, as these patients showed better-preserved arterial oxygenation than their counterparts with COPD alone. Lower $\mathrm{PCO}_{2}$ and impaired cerebral perfusion pressure (either due to low mean arterial pressure and/or cardiac output) emerge as the obvious culprits. Indeed, mean arterial pressure, a major determinant of cerebral blood flow [8], was reduced throughout the exercise tests and related to COx in COPD+HFrEF. Slight impairments in mean arterial pressure might reduce cerebral blood flow, particularly in the presence of impaired autoregulation and excessive sympathetic drive $[3,8]$. There is also some evidence that decreased cardiac output may impair exercise COx, independent of mean arterial pressure [8]. All patients were under cardioselective $\beta$-blocker therapy, and diminished heart rate response was the main mechanism for a reduced exercise cardiac output. This suggests a link between pharmacologically induced decrements in exercise chronotropic response and low exercise COx.

What is the practical relevance of these findings? Our data suggest that pharmacological treatment of HFrEF should take into consideration that the pre-frontal cortex is particularly sensitive to pressure perfusion impairments in patients with COPD. Impaired exercise $\triangle \mathrm{COx}$ is an independent prognostic factor in patients with cardiovascular disease and a predictor of cerebral ischaemic events [3]. It is noteworthy that stroke is more frequent in COPD patients when HFrEF coexists [9]. It is also conceivable that COx deficits reported herein would be observed in other clinical scenarios, such as acute exacerbations or diureticinduced hypovolaemia. Derangements in $\triangle \mathrm{COx}$ may also reduce motor output (central fatigue) and contribute to early exercise cessation [2]. In fact, $\Delta \mathrm{COx}$ was related to peak exercise capacity only in the COPD+HFrEF group. If future studies establish a cause-effect relationship, interventions aimed at improving cerebral blood flow during exertion might prove useful ergogenic aids for these patients.

Limitations of this study include its small sample size, heterogeneity of COPD severity, noninvasive determination of cardiac output, lack of cognition and cerebral blood flow measurements. It should be recognised, however, that $\Delta\left[\mathrm{HbO}_{2}\right]$ is not only a useful indicator of changes in intracerebral perfusion but also relates closely with cognition (reviewed in [10]). The COPD+HFrEF group showed less airflow 
obstruction than their counterparts with COPD. Thus, we might have underestimated the deleterious effects of HFrEF on cerebral haemodynamics in COPD. It also remains to be demonstrated whether impairment in $\mathrm{COx}$ in COPD+HFrEF is out of proportion to HFrEF alone.

In conclusion, this study provides novel evidence that the coexistence of HFrEF impairs cerebral oxygenation (and conceivably cerebral blood flow) during exercise in moderate-to-severe COPD. Additional studies are warranted to address whether this might be contributory to exercise intolerance and its clinical implications for prognosis, treatment and rehabilitation of the fast-growing population of patients with the COPD+HFrEF overlap.

\section{0} @ERSpublications

Exercise capacity and cerebral oxygenation are reduced in COPD-heart failure overlap compared to COPD in isolation http://ow.ly/nKfsg

Mayron F. Oliveira ${ }^{1}$, Flavio Arbex ${ }^{1}$, Maria Clara N. Alencar ${ }^{1}$, Aline Soares ${ }^{1}$, Audrey Borghi-Silva $^{1,2}$, Dirceu Almeida $^{3}$ and J. Alberto Neder ${ }^{1,4}$

${ }^{1}$ Pulmonary Function and Clinical Exercise Physiology Unit (SEFICE), Dept of Medicine, Division of Respiratory Diseases, Federal University of Sao Paulo (UNIFESP), Sao Paulo, ${ }^{2}$ Cardiopulmonary Physiotherapy Laboratory, Nucleus of Research in Physical Exercise, Federal University of São Carlos, São Carlos, and ${ }^{3}$ Dept of Medicine, Division of Cardiology, UNIFESP, Sao Paulo, Brazil. ${ }^{4}$ Laboratory of Clinical Exercise Physiology (LACEP), Dept of Medicine, Division of Respiratory and Critical Care Medicine, Queen's University, Kingston, Canada.

Correspondence: J.A. Neder, Division of Respiratory and Critical Care Medicine, Dept of Medicine, Queen's University and Kingston General Hospital, Richardson House, 102 Stuart Street, Kingston, K7L 2V6, ON, Canada.

E-mail: nederalb@gmail.com

Received: May 282013 | Accepted after revision: July 072013 | First published online: July 302013

Conflict of interest: None declared.

\section{References}

1 Rutten FH. Diagnosis and management of heart failure in COPD. In: Rabe F, Wedzicha JA, Wouters EFM, eds. COPD and Comorbidity. Eur Respir Monogr 2013; 59: 50-63.

2 Verges S, Rupp T, Jubeau M, et al. Cerebral perturbations during exercise in hypoxia. Am J Physiol Regul Integr Comp Physiol 2012; 302: R903-R916.

3 Ekkekakis P. Illuminating the black box: investigating prefrontal cortical hemodynamics during exercise with nearinfrared spectroscopy. J Sport Exerc Psychol 2009; 31: 505-553.

4 Koike A, Itoh H, Oohara R, et al. Cerebral oxygenation during exercise in cardiac patients. Chest 2004; 125: 182-190.

5 Oliveira MF, Rodrigues MK, Treptow E, et al. Effects of oxygen supplementation on cerebral oxygenation during exercise in chronic obstructive pulmonary disease patients not entitled to long-term oxygen therapy. Clin Physiol Funct Imaging 2012; 32: 52-58.

6 Rodrigues MK, Oliveira MF, Soares A, et al. Additive effects of non-invasive ventilation to hyperoxia on cerebral oxygenation in COPD patients with exercise-related $\mathrm{O}_{2}$ desaturation. Clin Physiol Funct Imaging 2013; 33: 274-281.

7 Ferreira EM, Ota-Arakaki JS, Barbosa PB, et al. Signal-morphology impedance cardiography during incremental cardiopulmonary exercise testing in pulmonary arterial hypertension. Clin Physiol Funct Imaging 2012; 32: 343-352.

8 Ogoh S, Ainslie PN. Cerebral blood flow during exercise: mechanisms of regulation. J Appl Physiol 2009; 107: 1370-1380.

9 Kwon BJ, Kim DB, Jang SW, et al. Prognosis of heart failure patients with reduced and preserved ejection fraction and coexistent chronic obstructive pulmonary disease. Eur J Heart Fail 2010; 12: 1339-1344.

10 Rooks CR, Thom NJ, McCully KK, et al. Effects of incremental exercise on cerebral oxygenation measured by nearinfrared spectroscopy: a systematic review. Prog Neurobiol 2010; 92: 134-150. 